\title{
Characterization of microsatellite markers in cassava based on microsatellite-AFLP technique
}

\author{
S. Whankaew ${ }^{1}$, S. Sraphet ${ }^{1}$, R. Thaikert ${ }^{1}$, D.R. Smith ${ }^{1}$ and \\ K. Triwitayakorn ${ }^{1,2}$ \\ ${ }^{1}$ Institute of Molecular Biosciences, Mahidol University, \\ Nakhon Pathom, Thailand \\ ${ }^{2}$ Center for Cassava Molecular Biotechnology, Faculty of Science, \\ Mahidol University, Bangkok, Thailand \\ Corresponding author: K. Triwitayakorn \\ E-mail: mbktw@mahidol.ac.th
}

Genet. Mol. Res. 11 (2): 1319-1326 (2012)

Received March 4, 2011

Accepted August 8, 2011

Published May 15, 2012

DOI http://dx.doi.org/10.4238/2012.May.15.2

ABSTRACT. We developed molecular markers for cassava based on
the microsatellite-amplified fragment length polymorphism (M-AFLP)
technique. Twenty primer pairs were developed and used for the analysis
of 48 samples of Manihot species, consisting of M. esculenta (33), M.
esculenta ssp flabellifolia (3), M. chlorosticta (3), M. carthaginensis
(3), M. filamentosa (3), and $M$. tristis (3). Nine microsatellite loci
that were polymorphic among these Manihot species were identified,
giving 32 polymorphic alleles and from two to seven alleles per locus.
Unbiased and direct count heterozygosity varied from 0.0233 to 0.7924
and 0.0000 to 0.7083 , respectively. There was significant deviation (P
$<0.05$ ) from Hardy-Weinberg equilibrium at five loci. Genotypic data
from the Manihot species were subjected to genetic diversity analysis.
We found that $M$. chlorosticta and M. esculenta ssp flabellifolia were
the closest populations, while $M$. filamentosa and $M$. esculenta ssp
flabellifolia were the most divergent. Considering within $M$. esculenta,
the samples from Nigeria and Fiji were the most closely related, while
those from Venezuela and of unknown origin were the most divergent.
We conclude that the M-AFLP technique is an effective method for 
generating microsatellite markers that are useful for genetic diversity analysis in Manihot species.

Key words: Cassava; M-AFLP; Manihot species; Microsatellites

\section{INTRODUCTION}

Cassava (Manihot esculenta), a shrubby root crop, is one of the leading crops of the world and is important both as a food source and in industrial usage. Cassava ranks fourth among all crops in worldwide production (FAO, 2007), and as such has been the focus of significant research aimed at improving both the quality and the yield. In the past decade, molecular markers have become an important tool for the study of genetic diversity of germplasm, which have immediate value in selection as well as for improving the breeding programs called marker assisted selection (MAS) (Charcosset and Gallais, 2003). Molecular markers are therefore being developed in many plants, including cassava.

Microsatellites, also known as simple sequence repeats (SSRs), are one of the most favorable molecular markers because of their high degree of polymorphism, co-dominant inheritance and the presence of abundant sequences dispersed throughout most of the genome (Morgante and Olivieri, 1993; Zane et al., 2002). These features have made them powerful markers for both genetic diversity studies and MAS (Varshney et al., 2005), and they have been used in many plant species (Roubos et al., 2010; Turkoglu et al., 2010; Iqbal et al., 2011). The major disadvantage in using microsatellite markers is that they require de novo development in most species (Zane et al., 2002). Traditionally, microsatellite marker development has involved genomic library construction and screening. This is both time-consuming and expensive (Fisher et al., 1996; Hayden and Sharp, 2001), and moreover, the recovery rate of useful microsatellite markers is generally low. In addition, predetermination of the copy number of microsatellite loci is not possible (Hayden and Sharp, 2001). An alternative approach to overcome these limitations is the microsatellite-based amplified fragment length polymorphism (M-AFLP) technique, a PCR-based approach that combines the concept of AFLP with the microsatellite anchor primer technique (Van Eijk et al., 2001; Yang et al., 2001; Acquadro et al., 2005) through a two-step "primer extension", which offers the rapid development of SSR markers at a lower cost (Van Eijk et al., 2001).

For cassava, previous studies have developed microsatellite markers based on genomic DNA libraries (Mba et al., 2001) and expressed sequence tag databases (Tangphatsornruang et al., 2008; Raji et al., 2009). In this study, we report a new set of microsatellite markers for cassava and other Manihot species, developed based on the M-AFLP technique and their application in genetic diversity analysis.

\section{MATERIAL AND METHODS}

\section{Plant materials}

Genomic DNA of 33 accessions of $M$. esculenta from 17 different countries, namely Thailand (2), Argentina (3), Brazil (2), Peru (2), Venezuela (1), Columbia (2), Mexico (4), Cuba (2), Paraguay (2), Ecuador (2), Guatemala (2), Malaysia (2), Nigeria (2), China (1), Fiji 
(1), Panama (1), Bolivia (1), and an unknown country (1), and 3 accessions each of $M$. esculenta ssp flabellifolia, M. chlorosticta, M. carthaginensis, M. filamentosa, and M. tristis, which were provided by the International Center for Tropical Agriculture (CIAT), was isolated from young leaf tissue using the DNeasy Plant Mini kit (QIAGEN, Hilden Germany).

\section{M-AFLP development}

Genomic DNA of the cassava variety "Hanatee" was digested with EcoRI and MseI enzymes, and ligated with EcoRI and MseI adapters, followed by pre-amplification reactions according to Vos et al. (1995). To generate the forward primer sequences, selective amplifications were carried out using nine primer combinations of three EcoRI adapter primers with three selective nucleotides (ACC, ACG and ACA) and three 5'-anchored microsatellite primers $\left[\mathrm{GTCG}(\mathrm{AG})_{7}, \mathrm{GACG}(\mathrm{TG})_{7}\right.$, and $\left.\mathrm{CAGC}(\mathrm{TC})_{7}\right]$, as described by Albertini et al. (2003). The reactions were set up in a total volume of $20 \mu \mathrm{L}$ containing $2 \mu \mathrm{L}$ of a 1:50 dilution of the amplified PCR products, $0.2 \mathrm{mM}$ of each dNTP, $1.5 \mathrm{mM} \mathrm{MgCl}_{2}, 10$ pmol of each primer and $1 \mathrm{U} \mathrm{Taq}$ polymerase (Promega) in the manufacturer-supplied buffer. Amplified fragments were separated on a 5\% denaturing polyacrylamide gel (Sambrook and Russell, 2001) and visualized by silver staining (Benbouza et al., 2006). Selected M-AFLP fragments were excised from the gel and incubated at $37^{\circ} \mathrm{C}$ for $2 \mathrm{~h}$ in $20 \mu \mathrm{L}$ sterile distilled water, and re-amplified. The purified PCR products were cloned into pGEM-T easy vector (Promega), then transformed to Escherichia coli DH5 $\alpha$ cells by the heat shock method (Sambrook and Russell, 2001). Plasmid DNA-containing M-AFLP fragments were sequenced, and forward primers were designed from the derived sequences using the Primer 3 program (http://frodo. wi.mit.edu/primer3/).

To generate the reverse primer sequences, the genomic DNA ligated to EcoRI and $M s e I$ adapters from above was used as a template for amplification with the newly designed forward primers (also from above) in combination with MseI adapter-directed primers with no selective nucleotide in order to amplify the opposite side of the microsatellite flanking sequence using the approach described by Acquadro et al. (2005). PCR was carried out in a total volume of $20 \mu \mathrm{L}$ containing $10 \mu \mathrm{L}$ DNA template, $0.2 \mathrm{mM}$ of each dNTP, $1.5 \mathrm{mM}$ $\mathrm{MgCl}_{2}, 10 \mathrm{pmol}$ of each primer and $1 \mathrm{U} \mathrm{Taq}$ polymerase (Promega) in the manufacturersupplied buffer. PCR cycles were performed as follows, $94^{\circ} \mathrm{C}$ for 2 min, then 35 cycles of $94^{\circ} \mathrm{C}$ for $30 \mathrm{~s}, 55^{\circ} \mathrm{C}$ for $45 \mathrm{~s}$ and $72^{\circ} \mathrm{C}$ for $1 \mathrm{~min}$, and ending with $72^{\circ} \mathrm{C}$ for $5 \mathrm{~min}$. Amplified products were separated on 5\% denaturing polyacrylamide gels and specific fragments were excised from the gel before cloning and transformation to E. coli DH5 $\alpha$, as described above. Nucleotide sequences of the fragment were analyzed and used to design the reverse primers.

\section{Analysis of M-AFLP markers}

All developed primers were tested for amplification with the donor species and tested for polymorphism within M. esculenta and among Manihot species. The analysis was performed in a total volume of $20 \mu \mathrm{L}$ containing $25 \mathrm{ng}$ genomic DNA, 10 pmol of each forward and reverse primer, $0.2 \mathrm{mM}$ of each dNTP, $1.5 \mathrm{mM} \mathrm{MgCl}_{2}, 1 \mathrm{U}$ Taq polymerase (Promega) in the manufacturer-supplied buffer. The PCR conditions consisted of $94^{\circ} \mathrm{C}$ for $2 \mathrm{~min}$, followed by 35 cycles of $94^{\circ} \mathrm{C}$ for $30 \mathrm{~s}, 55^{\circ} \mathrm{C}$ for $45 \mathrm{~s}$ and $72^{\circ} \mathrm{C}$ for $1 \mathrm{~min}$, and ending with $72^{\circ} \mathrm{C}$ for 5 
min. The PCR products were separated on 5\% denaturing polyacrylamide gels (Sambrook and Russell, 2001) and visualized by silver staining (Benbouza et al., 2006). A 100-bp + 1.5-kb DNA ladder (SibEnzyme) was used to define allele sizes.

\section{Data analysis}

Genotypes were scored manually according to country of origin and species. Allele frequencies were calculated followed by calculations of unbiased and direct count heterozygosities, Hardy-Weinberg equilibrium, the percentage of polymorphic loci (using the $95 \%$ criterion) and genetic distance using TFPGA 1.3 (Miller, 1997). The Mantel test was used to assess the association between Nei's unbiased $(1972,1978)$ genetic distance matrix and the Euclidian distance matrix using the same program. In addition, GENEPOP 4.0 (Rousset, 2008) was used for analysis of linkage disequilibrium.

\section{RESULTS AND DISCUSSION}

DNA of the cassava variety Hanatee that had been double-digested with EcoRI and $M s e$ I restriction enzymes was amplified by PCR with nine primer combinations of EcoRI plus three additional nucleotides and three 5'-anchored microsatellite primers. Selected M-AFLP fragments were isolated, cloned and sequenced in order to design specific microsatellite forward primers. These specific forward primers were then used together with MseI adapter primers to generate fragments containing the corresponding reverse sequences. These PCR products were cloned and sequenced and used to design specific microsatellite reverse primers.

In total, 20 primer pairs were developed, which successfully amplified genomic DNA of cassava variety Hanatee. From testing with Manihot species consisting of 33 accessions from M. esculenta and each of three accessions from M. esculenta ssp flabellifolia, M. chlorosticta, M. carthaginensis, M. filamentosa, and M. tristis, the results showed that 9 microsatellites displayed polymorphisms between Manihot species, with a total of 32 polymorphic alleles and allelic variation ranging from two to seven alleles per locus (Table 1). The heterozygosity of unbiased and directed count varied from 0.0233 to 0.7924 with an average of 0.3127 and from 0.0000 to 0.7083 with an average of 0.2143 , respectively. The analysis revealed that significant deviations $(\mathrm{P}<0.05)$ from Hardy-Weinberg equilibrium were observed at 5 loci (MAF222, MAF421, MAF512, MAF522, and MAF532). Significant linkage disequilibrium $(\mathrm{P}<0.05)$ was found between MAF413-MAF512, MAF512-MAF222, MAF512-MAF522, MAF513-MAF522, and MAF421-MAF522. Nei's genetic distance ranged from 0.0291 to 0.7724 . In support of this analysis, the data with UPGMA are shown in Figure 1. The results of genetic distance indicated that M. chlorosticta and M. esculenta ssp flabellifolia were the closest populations, while M. filamentosa and M. esculenta ssp flabellifolia were the most divergent.

Within a population of $M$. esculenta, seven polymorphic microsatellites were generated with a total of 24 alleles and allelic variation ranging from two to six alleles per locus. The genetic distances ranged from 0.0000 to 0.4895 (Figure 2). The closest relationship was found between M. esculenta from Nigeria and Fiji, while the samples from Venezuela and unknown origin were the most divergent. 


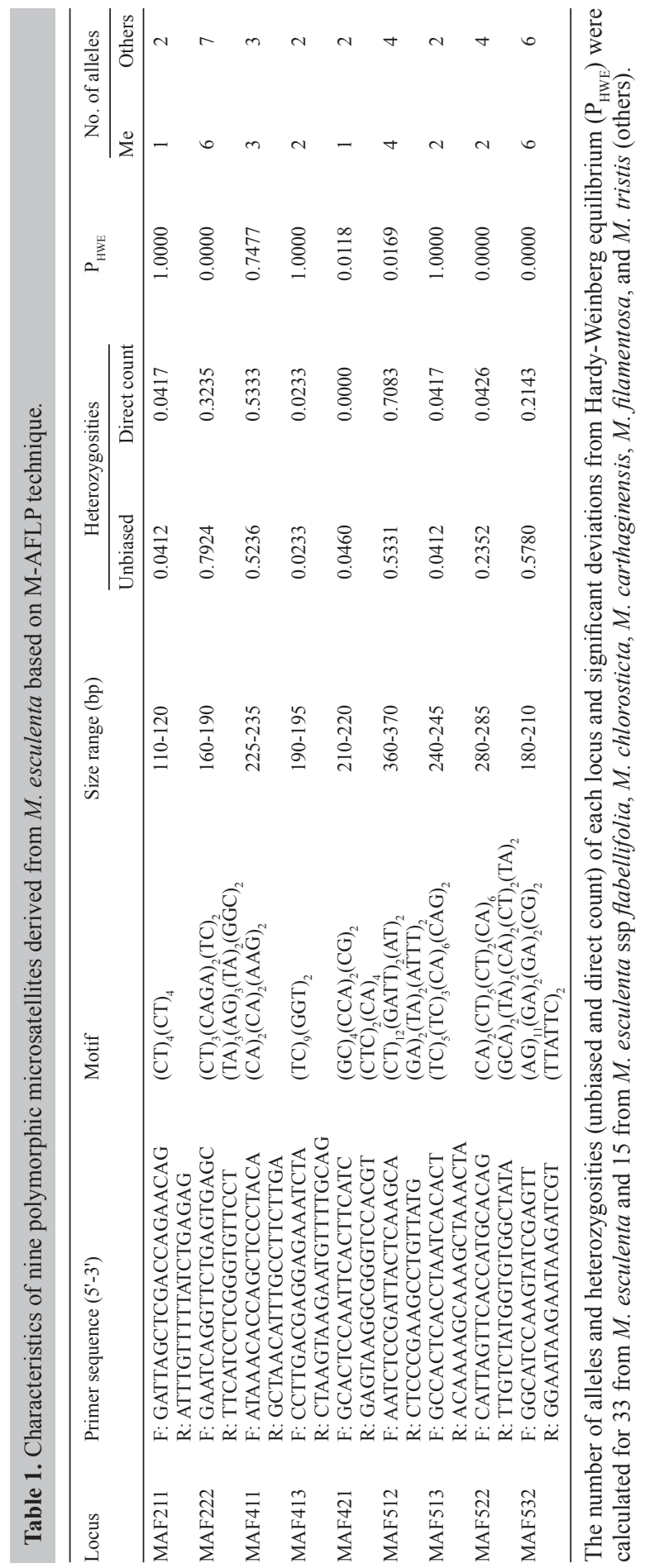



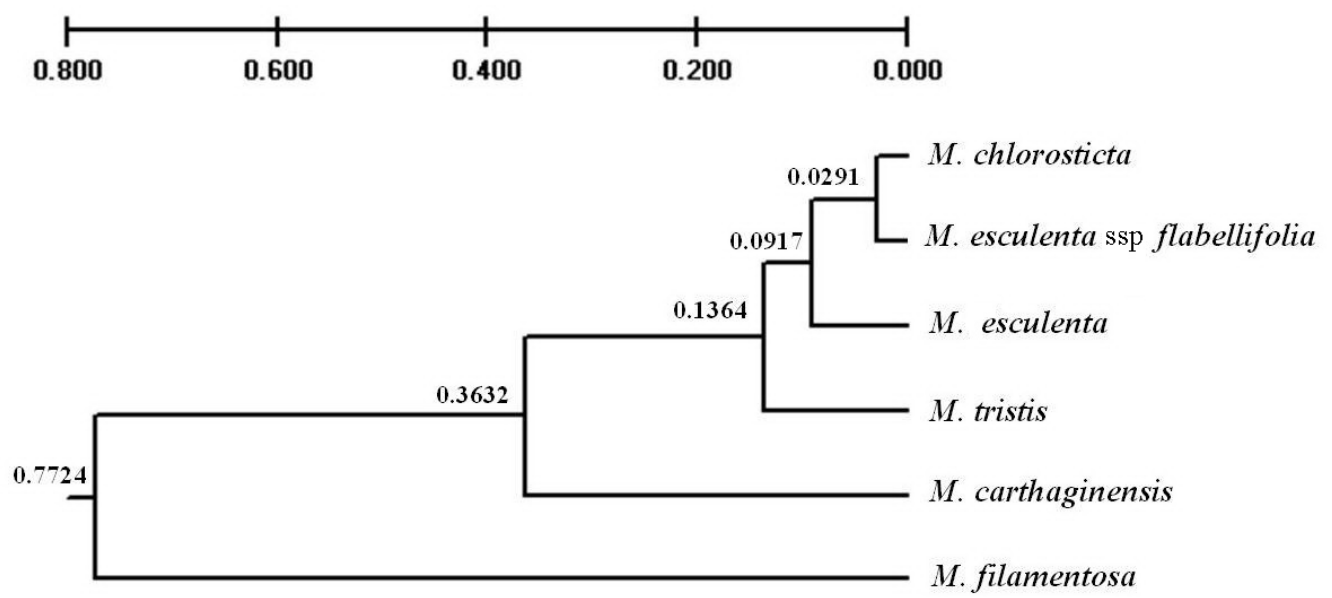

Figure 1. UPGMA dendrogram showing the genetic relationship between cassava accessions (Manihot esculenta) based on their landraces.

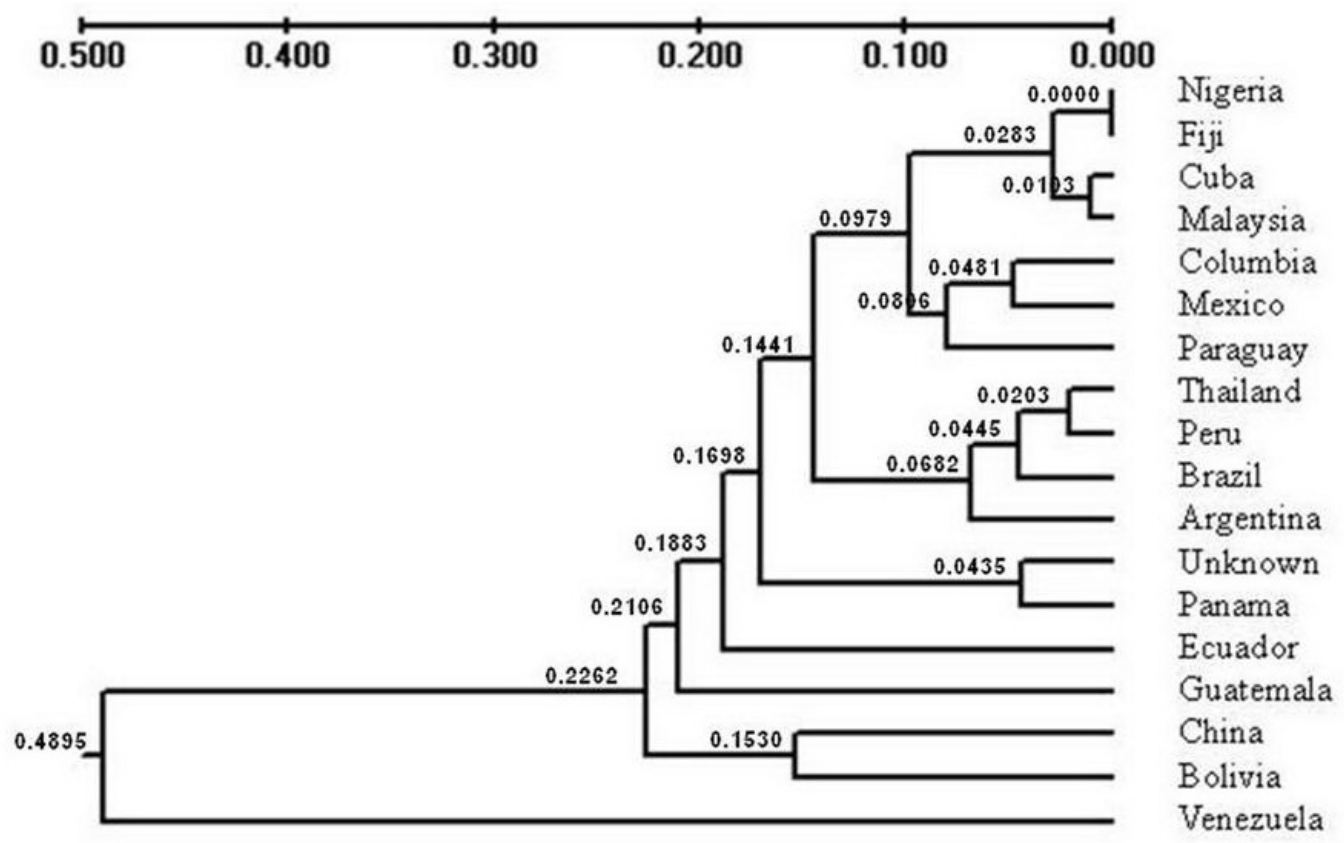

Figure 2. UPGMA dendrogram showing the genetic relationship between Manihot species.

In this project, new microsatellites were identified based on the M-AFLP technique. Nine of 20 microsatellite primer pairs $(45 \%)$ showed polymorphic patterns and were successfully applied to a genetic diversity analysis of Manihot species. In addition, seven microsatel- 
lite loci were useful for genetic diversity study of cassava. These microsatellites will be potentially applied in linkage mapping as well as comparative genome studies. The results of this study also suggest that M-AFLP technique provides a fast, inexpensive and effective method to develop microsatellites without the need for the construction of microsatellite-enriched libraries. This technique could be an alternative choice for marker development for cassava and other species.

\section{ACKNOWLEDGMENTS}

Research supported by the National Center for Genetic Engineering and Biotechnology, the Thailand Research Fund and Mahidol University. S. Sraphet and R. Thaikert received Ph.D. scholarship support from the Thailand Graduate Institute of Science and Technology and the Commission on Higher Education, Thailand, respectively. Financial support from the Thailand Research Fund through the Royal Golden Jubilee Ph.D. program (Grant \#PHD 4LMU/51/W1) to S. Whankaew and K. Triwitayakorn is acknowledged.

\section{REFERENCES}

Acquadro A, Portis E, Albertini E and Lanteri S (2005). M-AFLP-based protocol for microsatellite loci isolation in Cynara cardunculus L. (Asteraceae). Mol. Ecol. Notes 5: 272-274.

Albertini E, Porceddu A, Marconi G, Barcaccia G, et al. (2003). Microsatellite-AFLP for genetic mapping of complex polyploids. Genome 46: 824-832.

Benbouza H, Jacquemin J-M, Baudoin J-P and Mergeai G (2006). Optimization of a reliable, fast, cheap and sensitive silver staining method to detect SSR markers in polyacrylamide gels. Biotechnol. Agron. Soc. Environ. 10: 77-81.

Charcosset A and Gallais A (2003). Application of Markers in Selection. In: Molecular Markers in Plant Genetics and Biotechnology (Vienne Dd, ed.). Science Publishers Inc., New Hampshire, 153-176.

FAO (2007). Food Outlook - No. 1 June 2007. Available at [http://www.fao.org/docrep/010/ah864e/ah864e00]. Accessed October 28, 2008.

Fisher PJ, Gardner RC and Richardson TE (1996). Single locus microsatellites isolated using 5' anchored PCR. Nucleic Acids Res. 24: 4369-4371.

Hayden MJ and Sharp PJ (2001). Targeted development of informative microsatellite (SSR) markers. Nucleic Acids Res. 29: e44.

Iqbal A, Sadaqat HA, Khan AS and Amjad M (2011). Identification of sunflower (Helianthus annuus, Asteraceae) hybrids using simple-sequence repeat markers. Genet. Mol. Res. 10: 102-106.

Mba REC, Stephenson P, Edwards K, Melzer S, et al. (2001). Simple sequence repeat (SSR) markers survey of the cassava (Manihot esculenta Crantz) genome: towards an SSR-based molecular genetic map of cassava. Theor. Appl. Genet. 102: 21-31.

Miller M (1997). Tools for Population Genetic Analysis. Version 1.3. Department of Biological Sciences, Northern Arizona University, Flagstaff.

Morgante M and Olivieri AM (1993). PCR-amplified microsatellites as markers in plant genetics. Plant J. 3: 175-182.

Nei M (1972). Genetic distance between populations. Am. Nat. 106: 283-292.

Nei M (1978). Estimation of average heterozygosity and genetic distance from a small number of individuals. Genetics 89: 583-590.

Raji AA, Anderson JV, Kolade OA, Ugwu CD, et al. (2009). Gene-based microsatellites for cassava (Manihot esculenta Crantz): prevalence, polymorphisms, and cross-taxa utility. BMC Plant Biol. 9: 118.

Roubos K, Moustakas M and Aravanopoulos FA (2010). Molecular identification of Greek olive (Olea europaea) cultivars based on microsatellite loci. Genet. Mol. Res. 9: 1865-1876.

Rousset F (2008). Genepop'007: a complete re-implementation of the genepop software for Windows and Linux. Mol. Ecol. Res. 8: 103-106.

Sambrook J and Russell DW (2001). Molecular Cloning: A Laboratory Manual. 3rd edn. Cold Spring Harbor Laboratory Press, New York. 
Tangphatsornruang S, Sraphet S, Singh R, Okogbenin E, et al. (2008). Development of polymorphic markers from expressed sequence tags of Manihot esculenta Crantz. Mol. Ecol. Res. 8: 682-685.

Turkoglu Z, Bilgener S, Ercisli S, Bakir M, et al. (2010). Simple sequence repeat-based assessment of genetic relationships among Prunus rootstocks. Genet. Mol. Res. 9: 2156-2165.

Van Eijk M, De Ruiter M, Broekhof J and Peleman J (2001). Discovery and Detection of Polymorphic Microsatellites by Microsatellite-AFLP. In: IX Plant and Animal Genome Conference, San Diego, 143.

Varshney RK, Sigmund R, Borner A and Korzun V (2005). Interspecific transferability and comparative mapping of barley EST-SSR markers in wheat, rye and rice. Plant Sci. 168: 195-202.

Vos P, Hogers R, Bleeker M, Reijans M, et al. (1995). AFLP: a new technique for DNA fingerprinting. Nucleic Acids Res. 23: 4407-4414.

Yang H, Sweetingham MW, Cowling WA and Smith PMC (2001). DNA fingerprinting based on microsatellite-anchored fragment length polymorphisms, and isolation of sequence-specific PCR markers in lupin (Lupinus angustifolius L.). Mol. Breed. 7: 203-209.

Zane L, Bargelloni L and Patarnello T (2002). Strategies for microsatellite isolation: a review. Mol. Ecol. 11: 1-16. 